\section{Zink-Protoporphyrin in Erythrozyten}

\author{
A. M. Gressner ${ }^{1}$ und O. A. Gressner ${ }^{2}$ \\ ${ }^{1}$ Labor Dr. Wisplinghoff Berlin, Berlin, Deutschland \\ ${ }^{2}$ Labor Dr. Wisplinghoff Köln, Köln, Deutschland
}

Englischer Begriff zinc protoporphyrin in erythrocytes; red blood cell protoporphyrin; Zn-PP; ZPP

Definition Akkumulation von Zink-haltigem Protoporphyrin IX in $>$ Erythrozyten als Folge eines Defekts im terminalen Syntheseschritt des Häms (durch Ferrochelatase katalysierter Eiseneinbau in das Protoporphyrinringsystem), der durch Eisenmangel oder chronische $>$ Blei-Intoxikation bedingt ist.

Beschreibung Der von der $>$ Ferrochelatase katalysierte Einbau von Eisen in das Protoporphyrinringsystem mit Bildung von Häm, d. h. der letzte Schritt der Hämbiosynthese, wird durch chronische Bleiintoxikation und Pyridoxalphosphat-( $\triangleright$ Vitamin B6-)Mangelzustände inhibiert, da diese Bedingungen $\mathrm{zu}$ einer Hemmung der $\delta$-AminolävulinsäureDehydratase ( $>5$-Aminolävulinsäuredehydratase) und der Ferrochelatase führen. Weiterhin kommt es durch Eisenman- gel zu einer defizienten Hämsynthese. Anstelle von $>$ Eisen wird $>$ Zink mit niedrigerer Affinität in das Protoporphyrinringsystem eingebaut, wobei das entstehende Zink-Protoporphyrin Globin nicht bindet, daher frei in den $>$ Erythrozyten vorkommt. Die Bestimmung von ZPP in Vollblut oder vorzugsweise in gewaschenen Erythrozyten mit einem Hämatofluorometer bei einer Anregungswellenlänge von 405 nm und Emissionswellenlänge von $605 \mathrm{~nm}$ wird demzufolge zur adjuvanten (jedoch relativ unempfindlichen) Diagnostik einer chronischen Bleiintoxikation, eines Eisenmangelzustandes, einer ausgeprägten Hypovitaminose von Vitamin B6 (Pyridoxalphosphat) und einigen anderen Störungen der Hämsynthese eingesetzt. Der Referenzbereich ( $\triangleright$ Referenzbereich, biologischer) liegt für gewaschene Erythrozyten zwischen 19 und $38 \mu \mathrm{mol}$ ZPP/mol Häm. Im Vollblut werden höhere Referenzbereiche (30-70 $\mu \mathrm{mol} / \mathrm{mol}$ Häm) aufgrund interferierender fluoreszierender Substanzen gemessen. Konzentrationen zwischen 70 und $100 \mu \mathrm{mol} / \mathrm{mol}$ Häm sind typisch für $>$ Eisen-Mangelzustände.

\section{Literatur}

Sherwood R, Pippard MJ, Peters TJ (1998) Iron homeostasis and the assessment of iron status. Ann Clin Biochem 35:693-708 